(Stated mecting held Wednesday, November 20, I907.)

\title{
The Increased Gold Production and Its Effect Upon the Cost of Living.
}

By F. Lynwood Garrison,

Mining Engineer, Member of the Institute.

Within the past few months the question has been frequently raised, is not the enormous production of gold throughout the world responsible in some degree for the present extraordinary rise in prices of commodities, especially the necessities of life? This increase in the cost of living is apparently not confined to any one country, but is universal, at least in Europe and North America. The feeling seems to be pretty general that gold is being produced in such large quantities as to become cheap, in other words, the ratio between gold and food production has changed. It is possible to obtain approximately accurate figures relating to the gold element of the problem, but reliable statistics of the civilized world's food production do not seem to be available. We can safely assume, however, it is steadily increasing, and on the whole in perhaps no less degree than the growth of population. It will be necessary for us to further assume the ratio between the food supply and population a constant one, that is, one has not substantially gained upon the other during the past decade, although, of course, both have steadily increased.

Within the period from 1896 to I90o, the gold production of the world is given by the German statistician Soetbeer as $\$ \mathrm{I}, 286,505,000$, and in the five years between I90I and I905 was $\$ 1,611,155,000$. Taking the individual years we find the yield in 1896 was $\$ 202,251,600$; in $1897, \$ 236,073,700$, and in 1898 , $\$ 286,879,700$, showing a ratio of increase of approximately $16 \frac{3}{4}$ per cent. between 1896 and 1897 , and 2 I per cent. between 1897 and 1898 . The world's production of 1904 was $\$ 347,087,300$, 
and that for 1905 is officially given as $\$ 377,135,100^{*}$ an increase of approximately $8 \frac{1}{2}$ per cent. The estimated production for I 906 is $\$ 400,000,000, \dagger$ an increase of only 6 per cent. It would seem, therefore, that during the years of low prices and more or less business depression, the percentage of increase in gold production is nearly three times as large as in the years of great business expansion and high prices. This substantiates the dicta that within a period of public financial depression gold mining is one of the safest and most profitable occupations. It is evident from the above statistics that the actual increase during the years of low prices was much greater than in those of general prosperity. While obviously this does not slow that the accumulation of gold has not affected prices, it does demonstrate that in years of depression the gold output is greatly accelerated. The question hence arises, has the amassing of gold been greater than the demands of increased business? It is difficult to see how it could, since the larger the volume of business the greater demand there must be for a circulating medium of exchange.

Some persons appear to erroneously consicler that gold is an actual standard of value. It is of course in a sense an arbitrary one, the real standard being that of labor, the unit of which must be the amount of work a man can do in a given period, or, to use the words of Thoreau, "the cost of a thing is the amount of what I call life which is required to be exchanged for it." To support this life we must have food and when that increases in cost the price of labor must necessarily rise in like proportion.

Assuming that the general condition of trade throughout the world does not affect and is not influenced by the volume of gold production, the question arises, will the increase of the gold output keep pace with the demands for that precious metal, both for use as currency and consumption in the arts. Reviewing the production of gold in the United States in the year I906, which was $\$ 94,373,800$, we find that there has been a net increase over the year 1905 of $\$ 6,193,100$, nearly all of which is credited to Alaska. The older gold-producing States of California, Montana, South Dakota, and Washington show a decreased production of approximately $\$ 300,000$ each, and Colorado. Utah, and

* Report of Director of U. S. Mint for 1905, p. 37.

†Personal letter from Acting Director of U. S. Mint, October 22, 190\% 
Idaho a small decrease, Arizona a slight increase and Alaska and Nevada an enormous advance. The great gain in production of the vast and virgin territory of Alaska was perhaps to be expected, but the increased production of Nevada from $\$ 5,359$, 100 in 1905 to $\$ 9,278,600$ in 1906 was surprising, and is chiefly attributable to the remarkable discoveries of rich gold and silver ores in the Tonopah and Goldfield districts. It is doubtful, however, if this ratio of increase or even the same rate of production in Nevada can be maintained, since it is believed by well informed mining men that the yield of the Tonopah district has about reached its limit, as several of its best mines are showing signs of exhaustion. This is what might be expected from the injudicious manner in which some of these fine properties have been managed, or rather mismanaged.

In California hydraulic mining is not holding its own, and shows signs of dying out, whilst the dredging industry is increasing and has abundantly demonstrated its profitableness in favorable localities. In fact, it is safe to say that this form of gold washing and recovery is in its incipiency, and as it grows and develops, is certain to increase the gold production in many districts, thus materially assisting in maintaining a steady yield from the older producing areas. The quartz gold production in California has not substantially increased, but perhaps may do so as successful methods are developed for treating very lean ores. The writer cannot account for the falling off in the production of Colorado in 1906, as the labor troubles which so seriously affected the mining industry of that State appear to have been fairly well settled. It may be, that owing to the agitation produced by these disorders, capital has been scared away, and comparatively few new mining enterprises were inaugurated in Colorado. In Montana a large proportion of the gold production is from copper ores, and as this yield has steadily increased, the falling off in the gold output must be ascribed to other causes; in fact, since 1904 there has been a steady increase in copper and a marked decrease in gold production. In South Dakota the improvements and economies at the great Homestake mine seem to have failed to hold the gold production to a steady figure, since there has been a . decrease of $\$ 110,700$ between 1904 and 1905 , and of $\$ 309,000$ between 1905 and 1906. In Utah for 1906 over half of the $\$ 5$, I 30,900 of gold output was from copper ores. In Idaho the gold 
production is chiefly from placer mining, and showed a decrease between I905 and I906 of $\$ 39,900$. Except in Alaska there has been a decided falling off of the yields from placer or gravel mining as far as the United States is concerned. This is what might be expected, for placer and gravel washing is always the first mining system adopted when a new gold producing territory is opened up. After such alluvial deposits are exhxausted, the miner seeks for "quartz" gold or ledges, generally with unsatisfactory results, for such men are usually inexperienced in milling as well as under-ground mining. On the whole, it would appear that with the exception of Alaska placer or alluvial gold mining in the United States as an industry is dying out, and is giving way to dredging. The increased production of gold seems to be largely due to the copper ores, and to the exceptionally rich though somewhat erratic gold and silver deposits of central and southern Nevada. In this State it is doubtful if the present rate of production can be maintained, unless new gold deposits are discovered, and the expected large production of copper ores in the Ely district yields abundantly of the precious metals. While of course it would be unsafe to assert that the present ratio of gold production in the United States proper (not including Alaska) cannot be maintained, it is nevertheless difficult to see where the gold is to come from. Of Alaska we have reason to expect great things, for this vast territory is but partly explored, even in a geographical sense, but doubtless it also has its limitations.

Turning now to other parts of the world, we find that the gold yield of the Transvaal has about reached its maximum, since the best authorities appear to agree that it will from now on steadily decrease. The yield of this justly celebrated district is enormous, and is now considerably over $\$ 100,000,000$ per year. Other sections of South Africa are not very promising with the possible exception of Rhodesia, which in I905 yielded $\$ 7,224,605$. The gold production of Mexico is relatively not large, but there is reason to expect it will steadily increase. The same may be said of the Central American States and South America, which probably contain to-day the largest unexplored and undeveloped sections of the habitable earth.

In Europe, Russia is the only great gold producing country. The yield of European Russia and Siberia in I904 being 37,321 
kilos of gold, and in $1905,33,54 \mathrm{I}$, equivalent to $\$ 22,25 \mathrm{I}, 587$, the decrease in the year being ascribed to the disturbed political conditions of that country.

The conclusion is therefore unavoidable that the world's gold production has not reached an abnormal or unhealthy proportion when compared with the enormously increased commercial activities of the times. On the contrary, if anything, we need more gold, for business seems to have outgrown the supply of circulating medium, that is, coined money or currency. Gold is certainly not cheaper, and as some of the chief present sources of supply are exhibiting indubitable signs of exhaustion, it is not likely to become so. It is therefore evident that if the present rate of increase is to be maintained we must soon call upon the comparatively undeveloped fields of Siberia, Central and South America, and perhaps parts of Africa, although the prospects for gold in the latter country are not encouraging.

Continuing this analysis further, we find it is evident the quantity of gold derived from copper ores must be quite large. In the statistics for Arizona and California, this particular phase of the yield seems to be given only in terms of silver. that is, the amount of gold thus derived is not specifically stated. In Montana, however, $\$ 1,434,935$ of the total $\$ 4,889,233$ of gold produced by that State in 1905 came from the copper ores; that is, about 29 per cent. of the gold yield of the State was thus obtained. and in I906 it was probably much larger. New Mexico, for I905, gave $\$ 76,455$, or about 29 per cent., from copper ores, whilst in Oregon it was only ${ }^{\frac{1}{2}}$ per cent. Within the old gold producing States it seems we will in the future have to look to the dredging industry and the copper ores for the increase of gold production, if, in fact, we are not obliged to depend upon these sources to maintain the present amount and prevent a steady decline. The total yield of gold as an incident of the copper industry is evidently an important element, although the precious metals thus derived are proportionately very small and may be regarded as a by-product, since copper ores do not usually contain more than one or two dollars of gold and silver per ton, the ratio being about one part of gold to three or four of silver. The yield of these metals from this source will therefore 
depend upon the production of copper, which in turn is regulated by the price of that metal.

From a careful consideration of the whole subject, it is evident the gold production of the United States (not including Alaska) is not likely to continue exhibiting a substantial increase, if in fact it can maintain its present rate. There are doubtless many gold deposits of one kind or another in the United States that could be made to pay enormously in a country like China, where there is an abundance of cheap, and for the purpose, efficient labor, but in this country of high prices and extravagant living, such deposits would probably not yield a new dollar for an old one, even with the best of our so-called and sometimes over-rated labor-saving appliances. I believe it is an error to suppose modern mining and metallurgical methods can or will materially modify the gold production of the United States, although of course in some, and perhaps quite a number of instances, the yield of gold can in this way be increased, but as a factor of the whole question these modern innovations may be said to be comparatively umimportant.

Gold is not, as commonly supposed, a rare metal, indeed it is quite a common one in the crust of the earth, but it is exceedingly widely distributed and finely disseminated. It probably occurs in appreciable, though minute quantities throughout many, if not most of the Tertiary eruptive rocks that compose the vast chain of mountains extending from Alaska on the north to Tierra det Fuego on the south. The gravels underlying Philadelphia contain it, and the iridescent though dishonest scheme of Jernegan was based upon the substantial fact that gold does occur in sea water. The forces of Nature through millions of years have concentrated some of this gold in certain places favorable to its accumulation. By common process of erosion the particles of gold gather in stream beds, sea beaches and other alluvial and fluvial deposits. Through its solution in the circulating "waters under the earth" gold is carried from place to place in the rocks and precipitated in favorable locations, usually along with other metals. These latter phenomena are very obscure, but are slowly yielding to scientific study and research. In general, it may be said that the processes of metallic accumulation within the rocks. are essentially superficial in the sense that they are probably going on at no great distance below the surface. Metallic veins and deposits rlo not usually increase in size or richness with great depth. 
although there are of course some mines that can be worked about as far below the surface as our present mechanical limitations will admit.

In conclusion, it is difficult to see how the production of gold throughout the world can possibly continue to increase in the same rate as within the past few years, especially in the face of the continued increase in the price of labor, or to put it in another way, the cost of living. In the United States, especially in the manufacturing States like Pennsylvania, the land has been too frequently deserted by its tillers to labor in the factory, with a consequent increase in the cost of food and an absurdly high protective tariff has stimulated the manufacturing interests as alcohol will an individual, creating a brief sense of exhilaration followerl by its distressing but inevitable reaction. Extravagance saps the wholesomeness of family life, and if continued is certain to destroy the nation.

\section{GRANITE IN MAINE.}

During the summer of 1905, Mr. T. Nelson Dale, of the United States Geological Survey, visited all the important granite quarries in Maine. The results of this work are soon to be presented in a bulletin entitled "The Granites of Maine," to which Dr. George Otis Smith has contributed an introductory chapter and map showing the geographic and general reologic relations of the granites in that State. The bulletin will also include the statistics of the granite proriuction in Maine for 1905. prepared by Viss A. T. Coons.

The number of quarries and prospects visited, including those of "black sranite" for monumental use, amounted to 129 . The capital invested in the entire Maine granite industry in 1905 amounted to about $\$ 3,500,000$. This estimate is based upon fair valuations of the quarries themselves, of the plants, and of the amount of "working capital" that is required to carry on the present business.

The report is designed to be helpful to those who are engaged in quarrying and working granite, as well as to architects, contractors, and dealers in monumental stone, and it will also make known to geologists the results of such scientific observations as were made in the course of the work. In order to accomplish these various purposes it has been divided into two parts-a scientific and an economic part.

The first is practically a brief text-book on granite in general, illustrated by the quarries of Maine and written as far as has been possible in untechnical, granite language, so as to be intelligible to working and business men. This part treats of the origin, mineralogical and chemical composition, texture, structure. physical properties, and classification of 